\title{
Application of building information modeling in designing fire evacuation - a case study
}

\author{
Kun-Chi Wang ${ }^{a}$, Shih-Yu Shih ${ }^{b}$, Wen-Shuo Chan ${ }^{c}$, Wei-Chih Wang ${ }^{d}$, Shih-Hsu Wang ${ }^{e}$, Abdoul- \\ Aziz Gansonre ${ }^{b}$, Jang-Jeng Liu ${ }^{c}$, Ming-Tsung Lee ${ }^{c}$, Yuan-Yuan Cheng ${ }^{f}$, and Ming-Feng Yeh ${ }^{f}$ \\ ${ }^{a}$ PhD Student, Department of Civil Engineering, National Chiao Tung University, Taiwan \\ ${ }^{b}$ MS Student, Department of Civil Engineering, National Chiao Tung University, Taiwan \\ ${ }^{\mathrm{C}}$ Engineering Assistant, National Synchrotron Radiation Research Center, Taiwan \\ ${ }^{\mathrm{d}}$ Professor, Department of Civil Engineering, National Chiao Tung University, Taiwan \\ e Assistant Professor, Department of Civil Engineering, ROC Military Academy, Taiwan \\ ${ }_{\mathrm{f}}^{\mathrm{f}}$ Assistant Engineer, National Synchrotron Research Center, Taiwan \\ E-mail: chi780118.cv00g@g2.nctu.edu.tw
}

\begin{abstract}
-
In recent years, the construction industry has been actively seeking for possible applications of Building Information Modeling (BIM), including the domain of building disaster-prevention management. BIM enables us to present a facility layout in threedimension (3D) and carry the disaster-prevention objects and information whereas the traditional approach can only be presented in two-dimension. Therefore, it could be possible to improve the traditional two-dimensional (2D) plane of building disaster-prevention management. By focusing on fire disaster, this study develops a BIM-based model to support disaster-prevention management. This model includes four modules: personnel safety evaluation, escape route planning, education and training, and equipment maintenance modules. The personnel safety evaluation module integrates BIM with a type of fire simulation software (Fire Dynamics Simulator), while the escape route planning module and safety education and training module help generate escape routes and emergency exits according to the 3D functions of BIM. The firefighting equipment maintenance module utilizes the information management ability provided by the BIM to demonstrate 3D location information and condition (maintenance records) of all fire equipment, to increase the quality of the safety education, and ensuring the all fire equipment are maintained in great condition. Above all, this proposed model is applied to a high-tech facility for testing its feasibility.
\end{abstract}

Keywords -

Building information modeling; disasterprevention management; evacuation routes;

\section{Introduction}

In order to ensure the safety of personnel, the disaster prevention management of buildings is what the construction industry has been focused on. The tasks includes the design of escape routes in the building, escape routes simulation, disaster prevention briefs, educational training etc. However, the conventional escape routes were usually demonstrated in 2D views, and educational trainings often take places with 2D visual aids to explain hazardous areas and escape routes. Average people are not able to interpret the drawings in a short period of time, to understand their exact position within the building and to select the appropriate escape exit.

In recent years, the construction industry has been actively developing the Building Information Modeling (BIM) technology under all its possible applications, including the domain of building disaster management (Eastman et al., 2011). BIM enables us to present a facility layout in three-dimension (3D) and carry the disaster-prevention objects and information whereas the traditional approach can only be presented in twodimension (2D). Therefore, it could be possible to improve the traditional two-dimensional (2D) plane of building disaster-prevention management.

This study uses fire disaster as an example to propose a disaster prevention management module based on BIM, and connect the module with FDS (Fire Dynamics Simulator, NIST, 2010). This way, the module can predict the time to evacuation, evaluate the safety of personnel, and assist on planning the escape routes using BIM. Finally, the module would present the escape routes in films to enhance the quality of educational training. 


\section{Archive Review}

\subsection{Fire Emergency Exit Indication}

Escape to safety can be defined as the emotional reaction of a personnel inside a building complex, trying to escape to safe zone via escape facilities or equipment within allowable time when a disaster happens (Lee, 2005). A British scholar, Marchant (1980), proposed that escape time can be classified into necessary escape time and allowable escape time. The necessary escape time should be shorter than what is allowable to ensure the safety of personnel. The main factors affecting the necessary escape time are escape facilities, the psychological spirit of those who escape, their physiology, behavioral change, and fire dynamic change, etc. To design escape exits, aisles, stairs, all these factors above should be carefully considered (Marchant, 1980).

According to the national standards, the recommended formula from the evaluation manual of building fire prevention and escape ability is used to estimate the escape time ( $t_{\text {escape }}$ ) required for the personnel inside the building. The formula is as followed:

$$
t_{\text {escape }}=t_{\text {start }}+t_{\text {travel }}+t_{\text {queue }}
$$

where, $t_{\text {start }}=$ evacuation starting time, $t_{\text {travel }}$ $=$ walking time, ${ }^{t_{\text {queue }}}=$ time of blocked exit.

Also, $t_{\text {start }}$ is calculated as $(\sqrt{\Sigma A} / 30)+3 ; t_{\text {travel }}$ is calculated as $\max \left(l_{i} / v\right) ; t_{\text {queue }}$ is calculated as $(\Sigma \rho A) /\left(\Sigma N_{\text {eff }} B_{s t}\right)$. Therefore, formula (1) can be modified as:

$$
t_{\text {escape }}=\left(\frac{\sqrt{\Sigma A}}{30}+3\right)+\max \frac{l_{i}}{v}+\frac{\Sigma \rho A}{\sum N_{\text {eff }} B_{s t}}
$$

Where, $\Sigma$ A = sum of area; $l_{i}=$ distance of any point to the exit; $\mathrm{v}=$ speed of walking; $\rho=$ personnel density; Neff $=$ effective flow coefficients; Bst $=$ width of exit.

In terms of allowable escape time $t_{\text {allowable }}$, the most common hazards in a fire scene are low oxygen level, flame radiation, and smoke (Xiao and Yen, 2001). Therefore, allowable escape time can use the hazard level index from SFPE (Safe Fire Protective Engineering) manual in Table 1 as a guideline (National Fire Protection Association, 2008).

\begin{tabular}{|c|c|}
\hline \multicolumn{2}{|c|}{ SFPE manual } \\
\hline Category & $\begin{array}{l}\text { Limits (hazardous } \\
\text { situation) }\end{array}$ \\
\hline Heat convection & $\begin{array}{l}\text { Temperature }>60 \\
\text { OC, risks of hazard }\end{array}$ \\
\hline Toxicity & 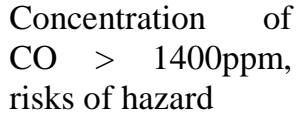 \\
\hline $\begin{array}{l}\text { Smoke covering } \\
\text { rate }\end{array}$ & $\begin{array}{l}\text { Visibility less than } \\
2 \text { meters, risks of } \\
\text { hazard }\end{array}$ \\
\hline
\end{tabular}

Table 1. definition of personnel hazard classification of

Note: The limit of hazardous situation means people exposure to hazardous for 30 minutes.

Furthermore, according to the evaluation manual of building fire prevention and escape ability, evacuation can be difficult while smoke layer height down to 1.8 meters from the ground. Therefore, the measurement points about smoke covering rate in Table 1 should be set at 1.8 meters from the ground(Wang, 2007).

\subsection{BIM application in Disaster Prevention Management}

By the information provided by BIM, users can make response when encountering disaster or emergency situation. For instance, the spatial information in BIM can help make judgment of the relationship between escape routes location and environmental hazards and thus reduce the uncertainty of emergency response (Zou and Wang, 2009; Rüppel and Schatz, 2011). Many national scholars classified the application of BIM on disaster prevention management into two categories: single building and multiple buildings (urban disaster). Some examples are as follows.

Chang (2011) combined BIM and online version of building fire surveillance system such as sensor, monitor, and spatial related information. When sensor is triggered, the management staff can identify the authenticity of the alarm through the system, find out the location of the fire so that the fire rescue would be effective and efficient in a large building.

Chen (2012) uses BIM for the maintenance work for fire equipment in a large building. Utilizing the information and history records of fire safety equipment in $\mathrm{BIM}$ and the $\mathrm{3D}$ visualization for the layout, the records are updated in the model, organized automatically and printed out as spreadsheets to simplify all excess works.

Chung (2012) put all the conventional investigation records of fire causes into spreadsheets, connected with BIM, and created a fire cause analysis system. Tablets, smartphones, and other kinds of portable devices are 
used to record the damage level and fire scene, and through wireless, can upload them to a database in order to help fire scene investigation crew to examine and analyze in the lab. This system not only increases the efficiency of process but also helps the foundation of future database and classification.

Lin et. al. (2009) use Taipei MRT (Mass Rapid Transit) as study subject and build a model of the train station using BIM software and buildingEXODUS escape software. Using urban streets as subject, Huang et. al. (2011) combines 3D visualized environment and time line to create a 4D dynamic simulation system to analyze the evacuation routes in the city. Considering human behaviors and environmental factors, the safety of the street area is evaluated by the crowdedness and by assigning a code of colors to the results, so that planners can based on the simulation results to select the appropriate evacuation routes.

\section{Disaster-Prevention model based on BIM}

Management

The disaster prevention management model proposed by the present study focus on the evacuation safety of the indoor personnel and evacuation equipment performance to do an overall evaluation. This model includes four prevention module: personnel safety evaluation, escape route planning, education and training, and equipment maintenance modules. The model structure is shown in Fig. 1. The overall is explained below and the following subsections, respectively give us the details of the contents of each module:

1. The personnel safety evaluation module evaluates the allowable escape time and required escape time. By comparing the results of the two values, we can determine the adequacy of the time for the staff to escape.

2. The escape routes planning modules utilizes the $3 \mathrm{D}$ information provided by the BIM model to determine the validity of the escape distance from each room, then select the exits.

3. The safety education and training module uses the distribution maps of hazardous areas to suggest that the disaster management personnel strengthens the inspection of the area. Then, the personnel is called to make a film of evacuation with the 3D escape direction map in order to better understand the escape routes.

4. The fire equipment maintenance module provides equipment information to the maintenance staff to enable them to complete more quickly firefighting equipment testing and replacement.

\subsection{Personnel safety evaluation module}

The personnel safety evaluation module combines fire dynamic simulation software (FDS) (NIST, 2010; Chung, 2012; Shih, 2013), in order to help evaluating the safety of personnel, which consists in ensuring that the required escape time is within the allowable escape time. Based on the results of the FDS simulation software and according to the personnel hazard classification of SFPE manual (Table 1), this module calculates the allowable escape time. On the other hand, it uses the formula (2) to calculate the required escape time (ABRI, 2004).

This module combines BIM with FDS to calculate the allowable escape time as described below:

1. 3D model of BIM: BIM models must necessary contain components such as columns, beams, walls, slabs, windows, doors, etc. The model level of development is the LOD 200 (Eastman et al., 2011) which is a 3D building massing including area, volume, height, and other basic information. The BIM models are converted into DWG file format and imported to the FDS software.

2. FDS fire simulation: set various combustion parameters, including: combustion reactants, heat release rate, fire source location, visibility and temperature measurement points, the simulation time, ambient temperature, etc. Among them, the visibility of the measuring points set at $1.8 \mathrm{~m}$ height from the ground floor, to view whether the visibility reaches the evacuation barrier height making escape conditions more difficult.

3. Allowable escape time: the FDS simulation results are interpreted according to the personnel hazard classification of SFPE manual (Table 1). The ambient temperature (limited to $60{ }^{\circ} \mathrm{C}$ ), carbon monoxide (limited to $1400 \mathrm{ppm}$ ) and the visibility (limited to 2 meters) are taken as indicators. Then, we respectively measure the time required to reach the limit indicator and choose the smallest value as the allowable escape time (Chung, 2003).

The required escape time is calculated as followed: 1. Spatial information parameters: retrieve the spatial parameters provided by the BIM model, including the total area of the room, the distance of any point within the room to the exit, the exit width etc.

2. Verification of the building fire prevention safety: the Formula (2) is the formula of the required escape time.

3. Required escape time: with the spatial information provided by the BIM, we can use equation (2) to calculate the required escape time.

Finally, we compare the allowable escape time and the required escape time, if is less than, then people should have sufficient time to escape the disaster site. 


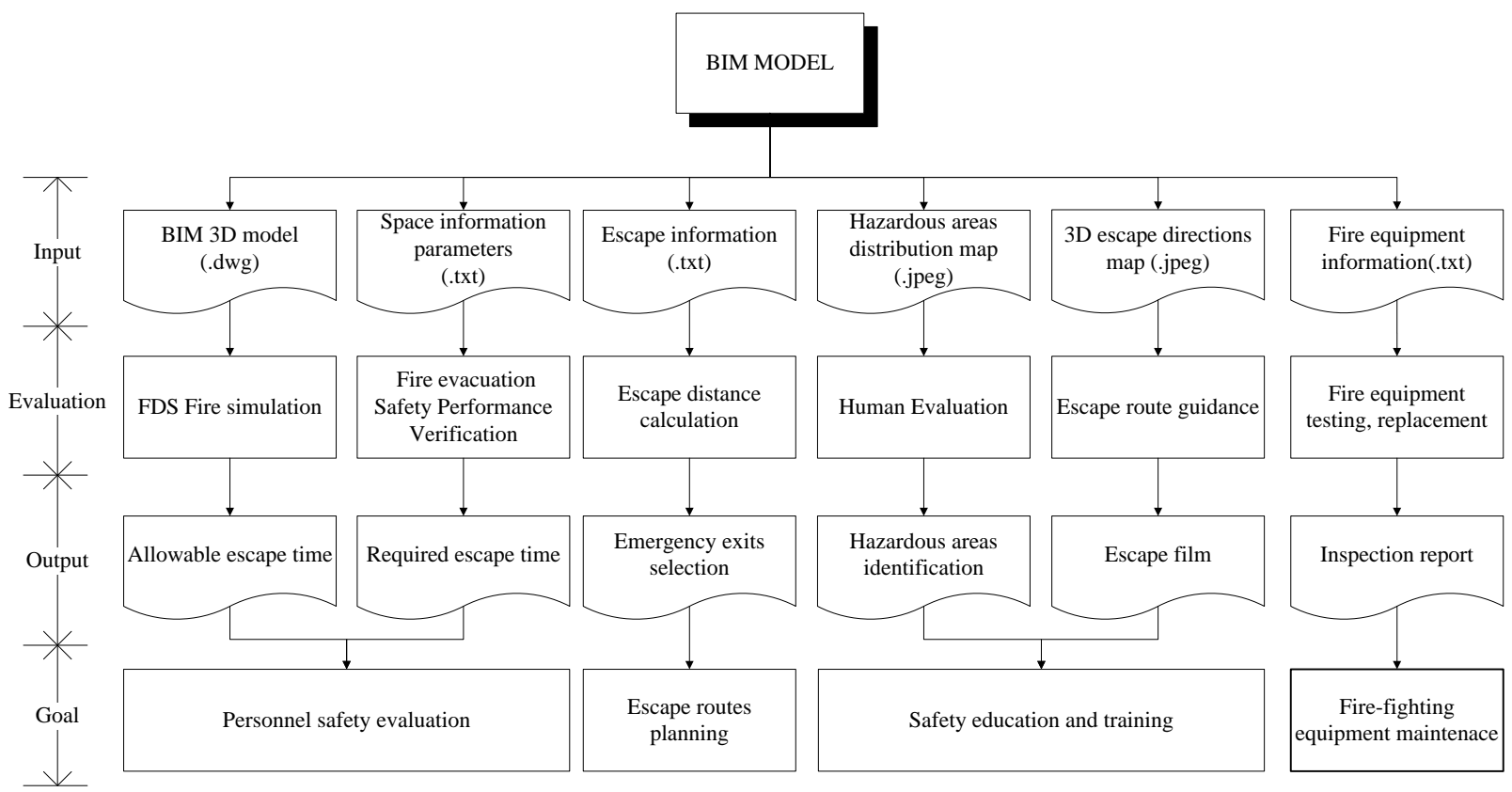

Figure 1. Disaster management structure chart based on BIM model

\subsection{Escape route planning module}

In accordance with the "Construction Technology Building Design and Construction Rules" (Ministry of the Interior, 2013), there is a maximum walking distance limit from any point within a room to the escape stairs. That is to say that the maximum distance for the personnel to reach to the evacuation exits depends on the different types of buildings.

The escape information provided by the BIM (such as: the name and level of each room, the nearby escape stairs and emergency exits) can help calculate the escape distance. In the BIM model, this module first selects the farthest room away from the stairs as the starting point, measure the distance to the stairs, determine whether the escape route is in accordance with the rules and plan the corresponding exits to each room within the building.

\subsection{Safety education and training module}

Safety education and training modules can be divided into two parts. The first part is about the safety training of the disaster prevention management staff. Building disaster prevention management staff must first sort out the areas that contain hazardous materials or areas likely to cause disasters. Then, through human judgment, they point out the areas with high disaster probabilities which are inserted into the BIM 3D model. The above procedure can help the management staff to ensure a good inspection and control of disasters.

The second part concerns the safety education and training of ordinary citizens. The complete planning of escape routes in 3D model are turned into 3D escape direction map in which the escape routes guidance are clearly shown. Finally, a film is made to improve the quality of the training and make citizens more aware on how to escape in case of a disaster.

\subsection{Maintain fire equipment module}

Except the fact that BIM models can provide disaster-related necessary evacuation and spatial information, it can also provide fire equipment maintenance information that can be effectively used by the maintenance personnel, such as: device name, type, last repair time, maintenance staff, exterior features, maintain records, equipment warranty, specifications, manuals, contracts regulations, equipment manufacturers, unit prices information and equipment components brands, rules, warranty manufacturers, location of fire-fighting equipment, equipment status and other information.

In the past, the basic information about these devices were often dispersed between the device manager, the device manufacturer and other parties, not integrated in a single platform, what could easily lead to data loss problems. Through all the information within a single BIM model, all the information will be passed to the fire-fighting equipment manager with the BIM model. When the fire-fighting equipment is damaged, fire equipment maintenance personnel can obtain such information in order to efficiently test the device and change if necessary. 


\subsection{Building the system}

For the implementation of BIM models as a strong base for the management of disaster, during it establishment, the BIM model shall be added to specific parameters or components in order to carry out the evaluation of each module. The model operations are described below:

- First, establish the BIM model into the LOD 200, at this point, the model contains columns, beams, walls, slabs and other basic structural elements, but it also contains the volume of buildings, height, opening dimensions and other information.

- Meanwhile, while doing the BIM model, draw the route from the escape stairs to the farthest room, then define each space within the building.

- In addition, in the model, add a variety of disaster prevention equipment and the need for equipment information fields, increasing the device name, type, time of last maintenance, maintenance staff, exterior features, maintain records, locations, specifications and other important information.

After completion of the above system, you can use the BIM model to the modules. Through the interaction of the BIM model and the information, we can assist the analysis of the four modules.

\section{Case study}

The present research case is about a high-tech factory facility in the northern part of Taiwan. The following sections describe the facility configuration status of the factory concerned and the application process of the proposed model in this research. Finally, through interviews with experts, we can evaluate the advantages and disadvantages of this model.

\subsection{Case facility configuration}

The circular building (refer to the study case building) of this public high-tech factory is shown in Fig. 2. The building facility configuration can be divided into inner ring (A zone), the shield tunnels (B zone) and outer ring ( $\mathrm{C}$ zone). The inner diameter and the outer diameter are approximately 65 meters and 110 meters while shielding tunnel is located between the inner and outer rings. The BIM model of the case study building has already been built during the construction phase, the building software is Autodesk Revit (2013).

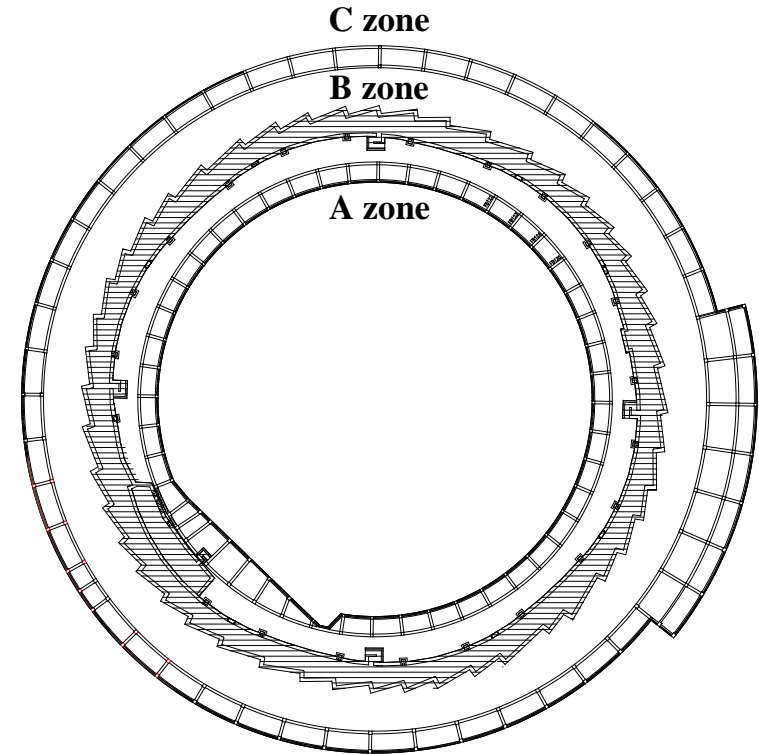

Figure 2. Case Building partition

The building is constructed on a slope, Fig. 3, the majority is about three floors (a small area is about four floors high), the building height is 14.7 meter. At the base level, the difference between the North and the south sides is approximately up to fourteen meters. About half the volume of the building is located under ground level, so the evaluation of personnel safety and evacuation planning is extremely important. Based on the particularity of the terrain, the evacuation floor can be established only at the second floor and above and it is extremely important to take into consideration the vertical moving line of evacuation. In the present building case, there is a total of 12 stairs leading to the ground floor to refuge, numbered S01 to S12, of which, S07 to S10 stairs are located in the inner ring, the rest of the stairs are located in the outer ring. For the evacuation floors located above the second floor of the building, the stairs constitute a very important escape equipment. Also, since this building study case is a circular structure, the interior space is very similar. So, in order to enable internal staff to quickly identify the current location, each column of the buildings is marked with a number (No.1 to No.48), known as columnnumber, and shown in Fig. 4.

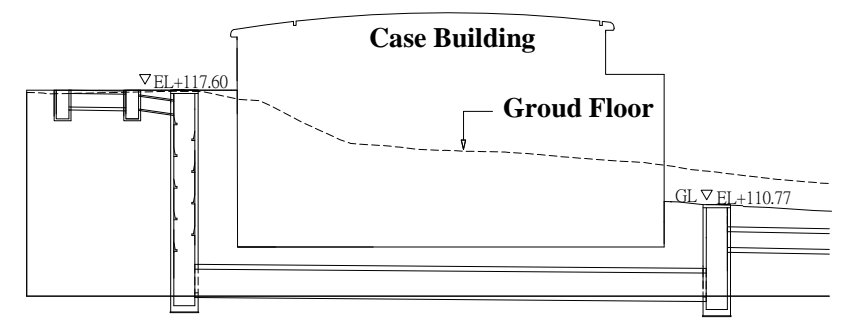

Figure 3. Schematic of the building north and south elevation difference 


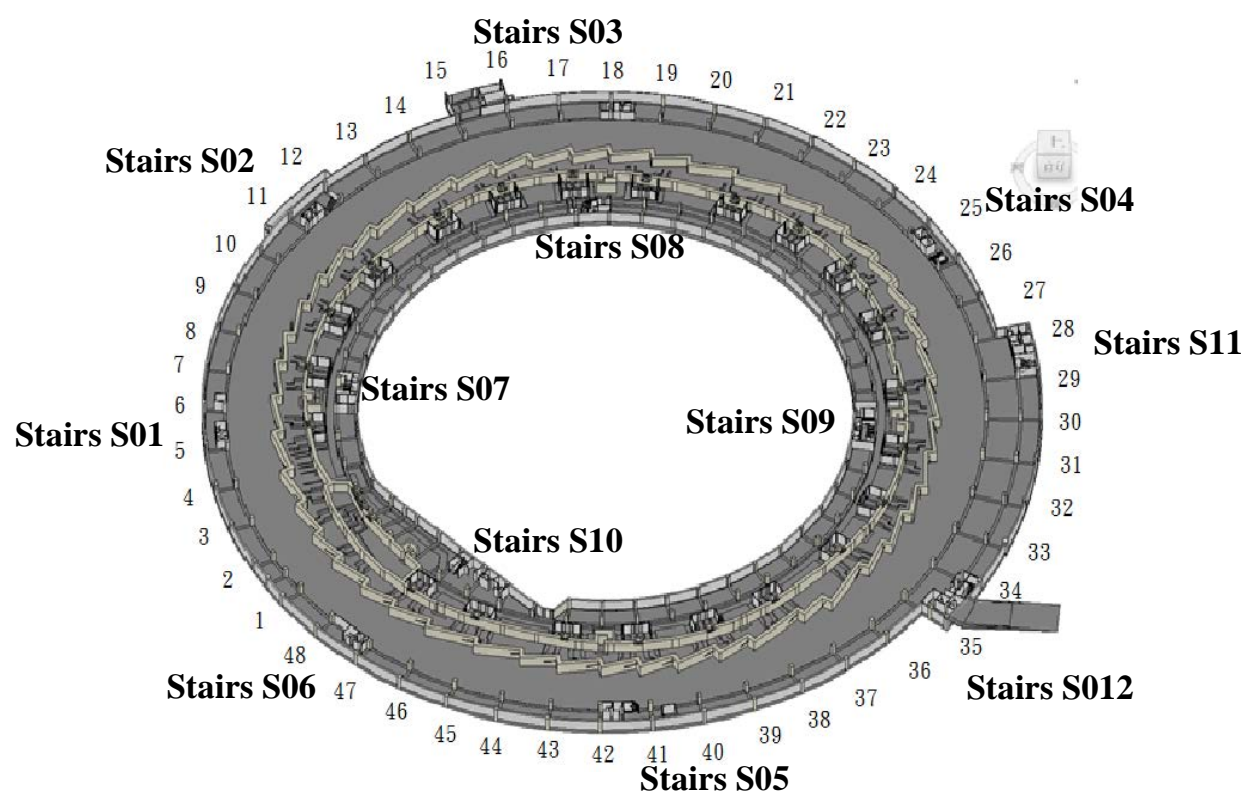

Figure 4. Building column and stairs distribution diagram

\subsection{Personnel safety evaluation}

First, this research will use the personnel safety evaluation module to facilitate the calculation of allowable escape time. In fact, the case building of the BIM model combined with FDS fire simulation software will simulate the circumstances of a fire in the building. To set the appropriate parameters in the FDS, it is important to first explore the building areas that are more likely to catch fire and the flammable items. It is also important to consider the most difficult evacuation areas of the building in case of fire. The following three points illustrate the ways of calculating allowable escape time:

1. BIM 3D model: convert the BIM model building into DWG format, then import into the FDS to transform it into FDS model, as shown in Fig. 5.

2. FDS fire simulation: during the simulation, the settings of each parameter begin with a more conservative value. In case of possible fire, the building has 58 engine rooms on the second floor: ventilation room, substations, computer control room and other engine rooms. In these Engine rooms, the connectivity between high voltage cables and electrical equipment, on a long term, is likely to lead to current overload caused by wires. So, after discussing with building fire prevention personnel, we reach to the conclusion that the engine rooms' area of the second floor have the higher probability of a disaster. Also, in this case, we consider that the high-voltage transformer substation is the fire ignition place and that the cables can be taken as fire items.

The visibility and temperature measurement points are set at the entrance of the escape stairs in order to estimate the personnel escape time.

We also use the double of the general electrical fires maximum heat release rate $(290 \mathrm{KW})$ which is equivalent to a safety factor of 2; the simulation time is 10 minutes and the ambient temperature is normal $\left(25{ }^{\circ} \mathrm{C}\right)$. And in the simulation, each space is set to be opened (no doors and windows) and fire compartments are not considered, the objective being to realize a fire simulation under conservative situations.

3. Allowable escape time: According to the results of the FDS simulation and corresponding to SFPE indicator level of personnel exposed to hazards (Table 1), we respectively identify the time required for temperatures to reach $60{ }^{\circ} \mathrm{C}$, the time for the carbon monoxide concentration to be higher than $1400 \mathrm{ppm}$ and the time required for a visibility less than for 2 meters. We then proceed to a comparison of the three values and we consider the minimum as the allowable escape time.

Next, we must calculate the required escape time; the following descriptions will show the ways to calculate the time required for the evacuation:

1. Spatial information parameters: to calculate the required escape time ( $\left.t_{\text {escape }}\right)$, we must provide the total area of the room, the distance between any point within the room to the exit, walking speed, occupant density, effective flow coefficient, the exit width and other information. Among them, the total area of the room, the distance between any point within the room to the exit, the exit width can be achieved in the BIM model, According to the BIM model of the case building, the total area of the room $(\Sigma \mathrm{A})$ is $372\left(\mathrm{M}^{2}\right)$; maximum 
walking distance (li) is 46 (M); exit width (Bst) is 1.64 (M). For the other parameters, we use the suggestions of the Architecture and Building Research Institute (Ho and Chien, 2008) including: walking speed (v) is 72 (M / min), personnel density ( $\rho$ ) o0.07 (persons / $\mathrm{M}^{2}$ ), the effective flow coefficient (Neff) of 90 (persons / min / $\mathrm{M})$.
2. Verification of the fire safety code of a building: in this case we use the formula (2) to calculate the time required for personnel to escape.

3. Calculate the required escape time: referring to the previous parameters collected, substituting into equation (2) to calculate.
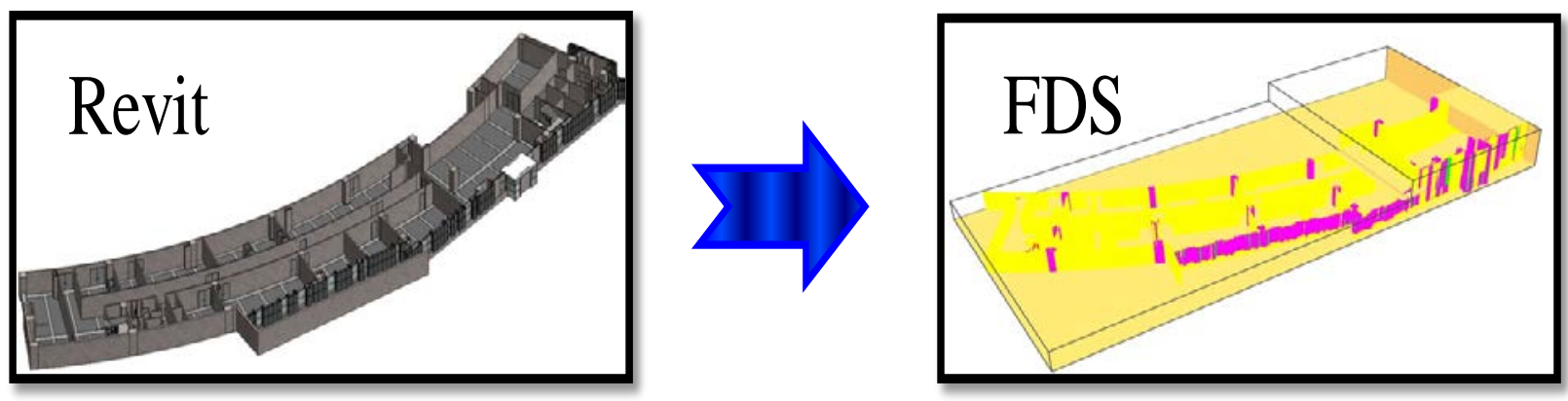

Figure 5. Schematic of the Revit model imported into FDS

\subsection{Planning escape routes}

The regulations specify only escape route walking distance. According to the Building Technical Regulations, article 93 of the rules of Building Design and Construction, the case building belongs to the industrial sector with a storage classified in the C type, the distance between the farthest room to the stairs must not be more than 70 meters (Ministry of the Interior, 2013). During the design stage of this case, the architect used manual calculations to check whether it meets the requirements (shih, 2013). In this study, we use the BIM model to determine the distance of the farthest room from the stairs and measure the distance between each stair (exits) and the farthest room. The objective is to test the distance between each space of the building and the exit in order to confirm the previous results of the manual calculations.

\subsection{Safety education and training}

In the safety education and training, the first part is about the training of the building prevention management personnel. The second part concerns the training of the working personnel.

1. Training of the disaster prevention management personnel: the case building contains many engine rooms. In order to help identify the engine rooms that are likely to lead to disaster, they should be marked out in the BIM model with characters. Then, with the help of the disaster prevention management personnel, we determine the hazards of each room according to its characteristics and identify the most hazardous room. On the second floor of the present building, there are all the different types of engine rooms. Many of these engine rooms contains multiple wire and combustible materials. Among them, the high pressure room is the most hazardous; so, we mark it in red in the BIM model in order to alert the maintenance staff about the importance to strengthen the inspection in this area.

2. Training of the working personnel: Referring to the escape routes planning, use the BIM model to create a 3D escape direction map including the guidance. Because the case building is a ring structure, the interior is very similar and it can easily cause confusion for the personnel. Therefore, in order to enable the personnel to quickly understand their location within the building and follow the correct escape routes in case of emergency, the column-numbers are clearly marked on the map (Fig. 6).

\subsection{Fire-fighting Equipment Maintenance}

In the case building, there are many people working and there is no doubt that their safety is very important. Therefore, in order to ensure the safety of the personnel, the indoor fire-fighting equipment must be maintained in good condition. The fire-fighting equipment used in the present case building are: fire extinguishers, fire hydrants, fire detectors, smoke extraction equipment, emergency lights, etc. Through the BIM model components, we can have all the information relative to the equipment maintenance to help conducting the firefighting equipment maintenance work.

\subsection{Discussions}

After the testing of the present case building in the model, the results are presented to the disaster prevention management staff for evaluation and their correlated suggestions are listed below: 


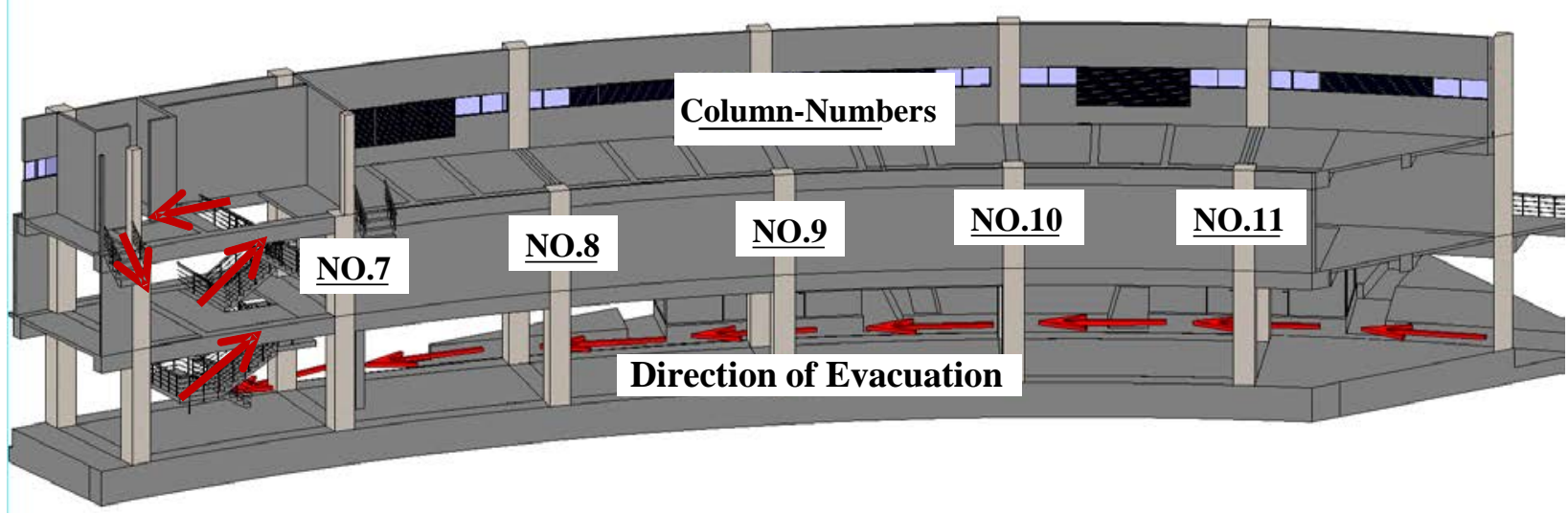

Figure 6. 3D escape directional map

1. The personnel safety evaluation module:

a. In the past, the 3D model was required to be set up before the FDS simulation, including structural components such as columns, beam, wall and slab. Besides, the procedure of establishing the model was complex, time-consuming and low accurate. The parameter of objects (length, wide, and high) always needed to be entered item by item. Through BIM model (especially if the BIM model has been included early in the construction phase), it is possible to save a lot of time during the modeling.

b. Due to the reliability of the space and size information provided by the BIM model, the results from the FDS simulation are more qualified for the actual situation.

2. Escape route planning module:

a. When planning escape routes, it is very important to take into consideration a variety of information, such as the evacuation floor, the exit location, the nearby escape stairs etc. All these different kinds of information don't have the same origin. Through the data access of the unique BIM model, we can significantly reduce the time required to collect data and increase the accuracy of the information.

b. The BIM can help measuring distance between the farthest room and the escape stairs and can provide a $3 \mathrm{D}$ visualization of the escape routes in order to avoid the design of impractical escape routes.

3. Safety education and training module:

By identifying the hazardous areas in the BIM model, the safety personnel can be aware about the necessity to strengthen the inspection of the high fire risks areas. (but, currently it can only be displayed in 2D; the $3 \mathrm{D}$ features could be an interesting option to be developed in the future).

4. Fire-fighting equipment maintenance module:

Using the parameterization function of the BIM model, the information and records of the disaster prevention equipment maintenance are collected in a unique model to assist the maintenance staff in the testing of the relative equipment. It can reduces the information collection time and ensure that each firefighting equipment is in the most favorable condition.

\section{Conclusions and Recommendations}

This study uses the BIM 3D architectural space configurations and the possibility to mount the information about disaster prevention in the model, to propose a significant improvement of the traditional use of $2 \mathrm{D}$ documents on the disaster prevention management. The study has been done through four main modules that are the personnel safety evaluation, the escape routes planning, the safety education and training, and the fire-fighting equipment maintenance. Through the analysis of the present case building, the proposed model should be feasible. The personnel safety evaluation combines the BIM and FDS to provide the allowable escape time in case of emergency and uses the BIM parameters to estimate the required escape time for the personnel, which should be a great academic innovation.

Following are the subsequent research directions.

1. In the domain of the personnel safety evaluation, the fire simulation considers only the geometry of the interior space, it did not consider wall material.

2. Concerning the escape routes planning, the BIM model only consider the restrictions of the Construction Technology Building Design and Construction Rules, not taking into account other regulatory norms, nor personnel psychological characteristics.

3. The current operation mode of the model has not been automated yet. So, establishing an automated system should enhance the effectiveness of its use. 


\section{Acknowledgements}

We would like to highlight the National Synchrotron Radiation Research Center (Project No.: SRPO1020091) and the National Science Council (Project No.: NSC101-2622-E-009-013-CC3) who partly funded the present study. We thank the Concord Tech Company for their support on the design technology, Autodesk that provided the BIM design software and the National Chiao Tung University research team for their help in the Building design work. We are also indebted to all the engineering experts who participated in one way or another to provid valuable information and practical experience.

\section{References}

[1] Autodesk, Autodesk, http://usa.autodesk.com, Accessed: 18/01/2013.

[2] Eastman, C., Teicholz, P., Sacks, R., and Liston, K., BIM Handbook: A Guide to Building Information Modeling for Owners, Managers, Designers, Engineers, and Contractors, Second Edition, John Wiley \& Sons, Inc., New Jersey, 2011.

[3] Huang, C. H. and Wu, I. C., "Applying 4D simulation in disaster evacuation route plan," In Proceeding of the International Conference on Construction Application of Virtual Reality, Weimar, Germany, 2011.

[4] Marchant, E. W., Modeling Fire Safety and Risk, Fire and Human Behavior, Edited by D. Canter, John Wiley \& Sons Ltd. New York. pp. 302, 1980.

[5] National Fire Protection Association, The SFPE Handbook of Fire Protection Engineering, 4th Edition, Quincy, MA, 2008.

[6] NIST, National Institute of Standards and Technology, http://www.nist.gov, Accessed: 22/05/2013.

[7] Rüppel, U. and Schatz, K., "Designing a BIMbased serious game for fire safety evacuation simulation," Advanced Engineering Informatics, Vol. 25, No. 4, pp. 600-611, 2011.

[8] Zou, Z. C. and Wang, Y. W., "Framework of spatial decision support system for large-scale public building evacuation," In Proceeding of theWRI Global Congress on Intelligent Systems (GCIS), IEEE, Xiamen, China, pp. 352-356, 2009.

[9] Architecture and building research institute, the evaluation manual of building fire prevention and escape ability, 2004, Taiwan, Taipei:Archbook.

[10]Ministry of Interior, Building Technical Regulations, 2013.

[11]Wang, P. C., A full scale experimental study on the assessment factors of room available safety egress time, $\mathrm{PhD}$ dissertation, National Taiwan University of Science and Technology, Department of Architecture, 2007.

[12] Shih, S. Y., Applying building information modeling in building disaster prevention and management, Master thesis, National Chiao Tung University, Department of Civil Engineering, 2013.

[13]Lee, W. C., The Study of Evacuation of Set House by the Case of Dasishi Fire, Master thesis, National Kaohsiung First University, Department of Safety, Health and Environmental Engineering, 2005.

[14]Ho, M. J. and Jian, X. W., The research of revising fire safety performance verification technical manual, A report commissioned by ABRI, 2008.

[15]Lin, C. H., Analysis of interface integration $-a$ BIM application on MRT underground station, master thesis, China University of Technology, Graduate Institute of Architectural Design, 2010.

[16]Chung, W. Y., The study simulation system design of evacuation in a building, master thesis, National Yunlin University of Science and Technology, Department of Mechanical Engineering, 2003.

[17]Chung, H. H., Application of building information model technology on the fire investigation process, Master thesis, National Central University, Department of Civil Engineering, 2012.

[18]Chen, Y. R., The study on BIM in fire safety equipment maintenance modes of building, National Taipei University of Technology, Master Thesis, Graduate Institute of Civil and Disaster Prevention Engineering, 2012.

[19]Chang, T. T., Combine BIM to develop building fire prevention monitoring system, Master thesis, Chung Hua University, Department of Construction Management, 2011.

[20] Xiao, J. B. and Yen, Y. N., A study on fire safety planning and acceptable solutions for reusing historic buildings, A report commissioned by ABRI, 2001. 